Supplement of

\title{
Measurement report: Altitudinal variation of cloud condensation nuclei activation across the Indo-Gangetic Plain prior to monsoon onset and during peak monsoon periods: results from the SWAAMI field campaign
}

Mohanan R. Manoj et al.

Correspondence to: Mohanan R. Manoj (manojshibika@gmail.com)

The copyright of individual parts of the supplement might differ from the article licence. 


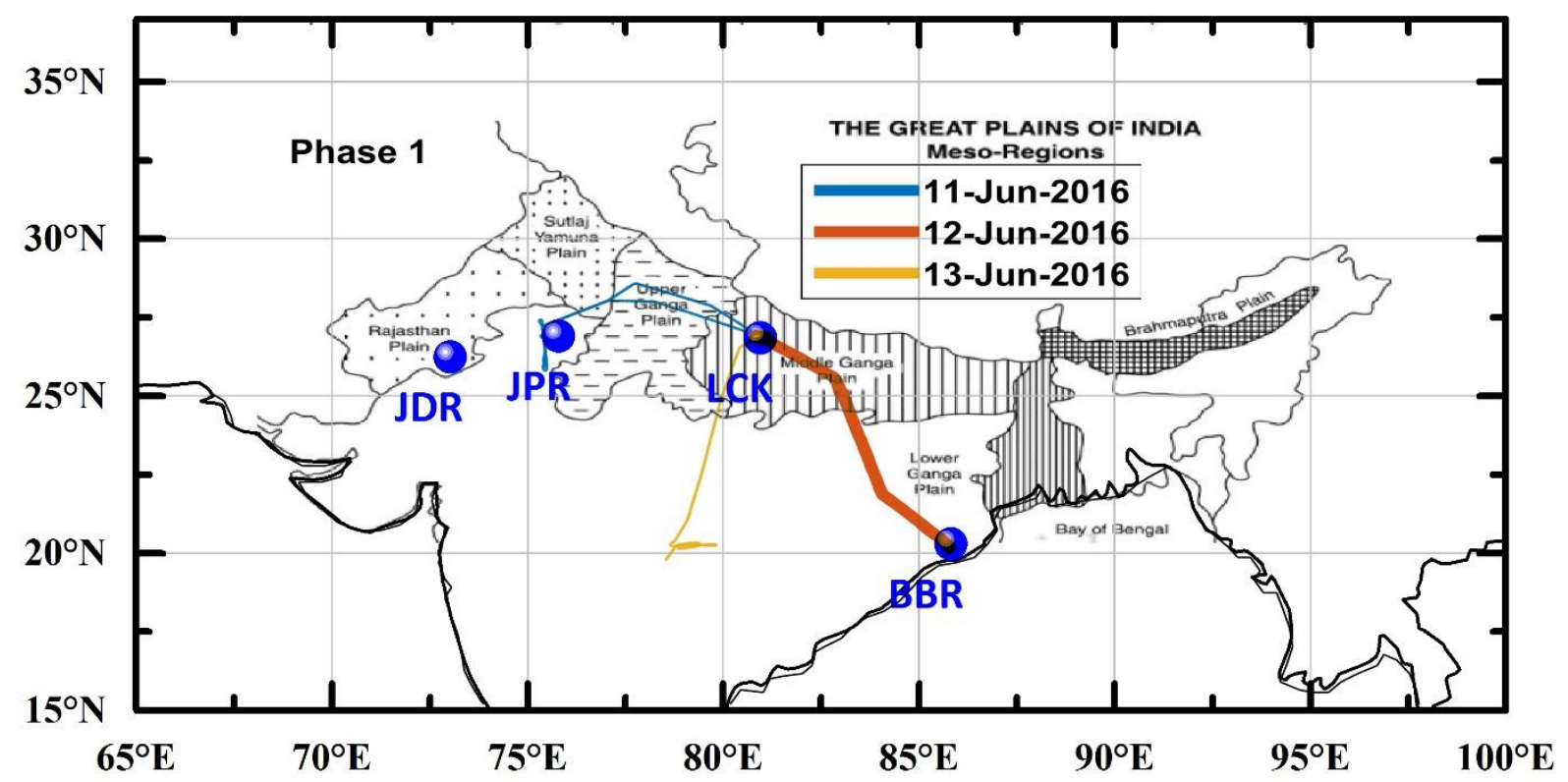

Figure S1: Flight track during phase 1 measurements. The map showing the geographical distribution of the great Indian plain is available at https://studywrap.com/the-northern-plains-of-india-great-plains-ofindia/\#The_Great_Plains_of_India. 


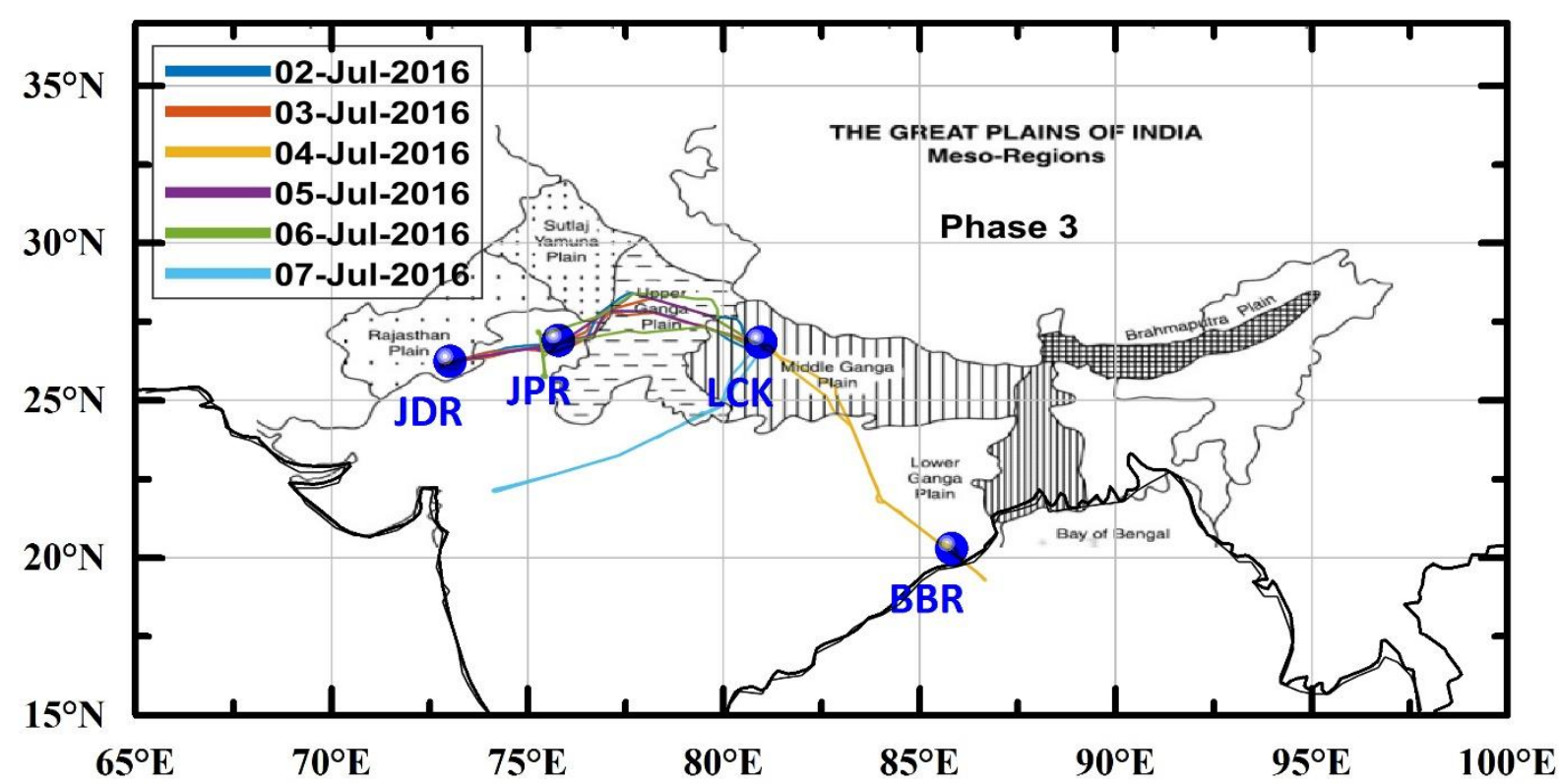

Figure S2: Flight track during phase 3 measurements. The map showing the geographical distribution of the great Indian plain is available at https://studywrap.com/the-northern-plains-of-india-great-plains-ofindia/\#The_Great_Plains_of_India. 


\section{NOAA HYSPLIT MODEL}

Backward trajectories ending at 0700 UTC 11 Jun 16 CDC1 Meteorological Data

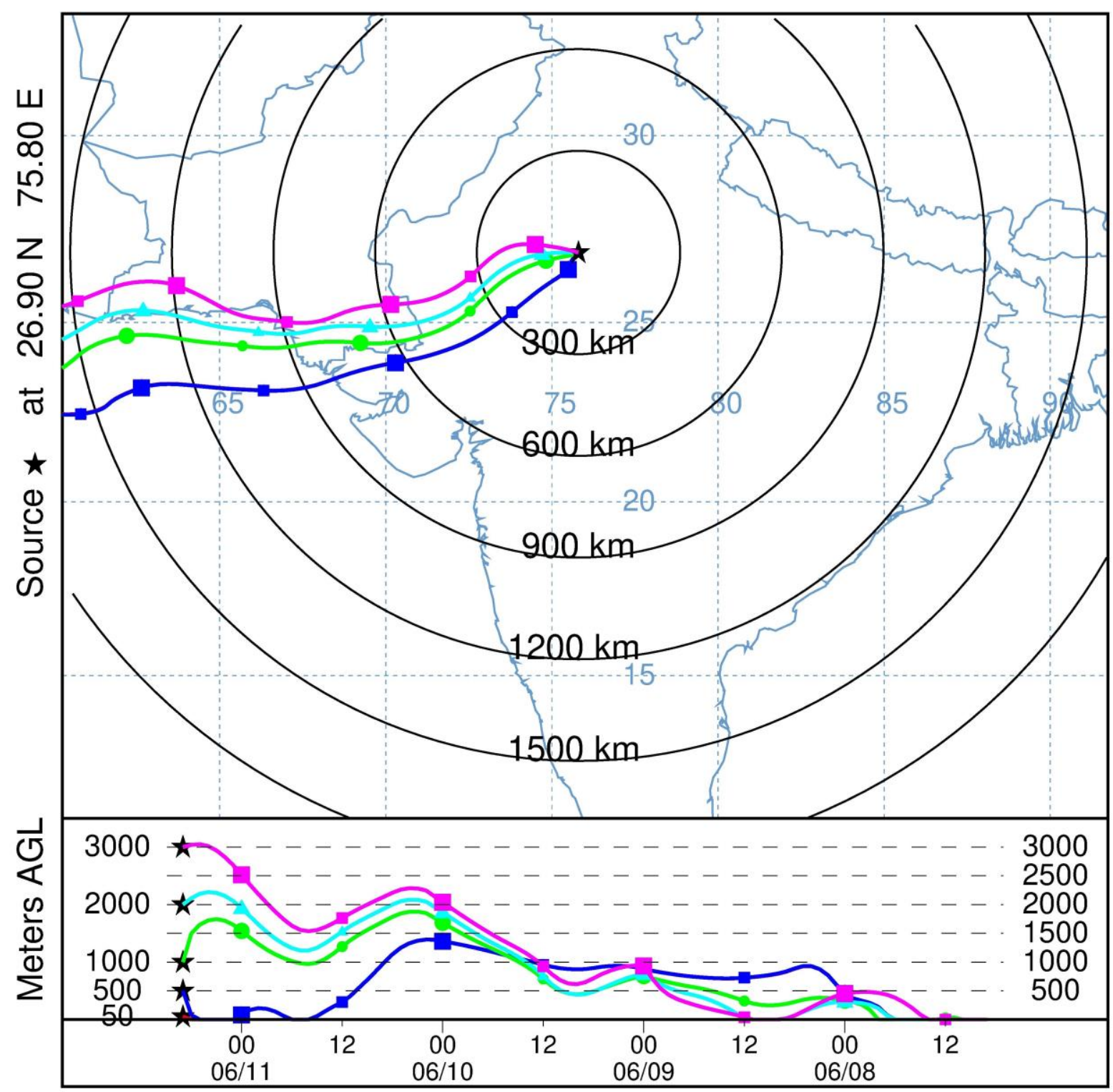

Figure S3: 96 hour back trajectory of air mass arriving at JPR on $11^{\text {th }}$ June at altitudes $50 \mathrm{~m}, 500 \mathrm{~m}, 1$ $\mathrm{km}, 2 \mathrm{~km}$ and $3 \mathrm{~km}$. 
NOAA HYSPLIT MODEL

Backward trajectories ending at 0700 UTC 11 Jun 16 CDC1 Meteorological Data

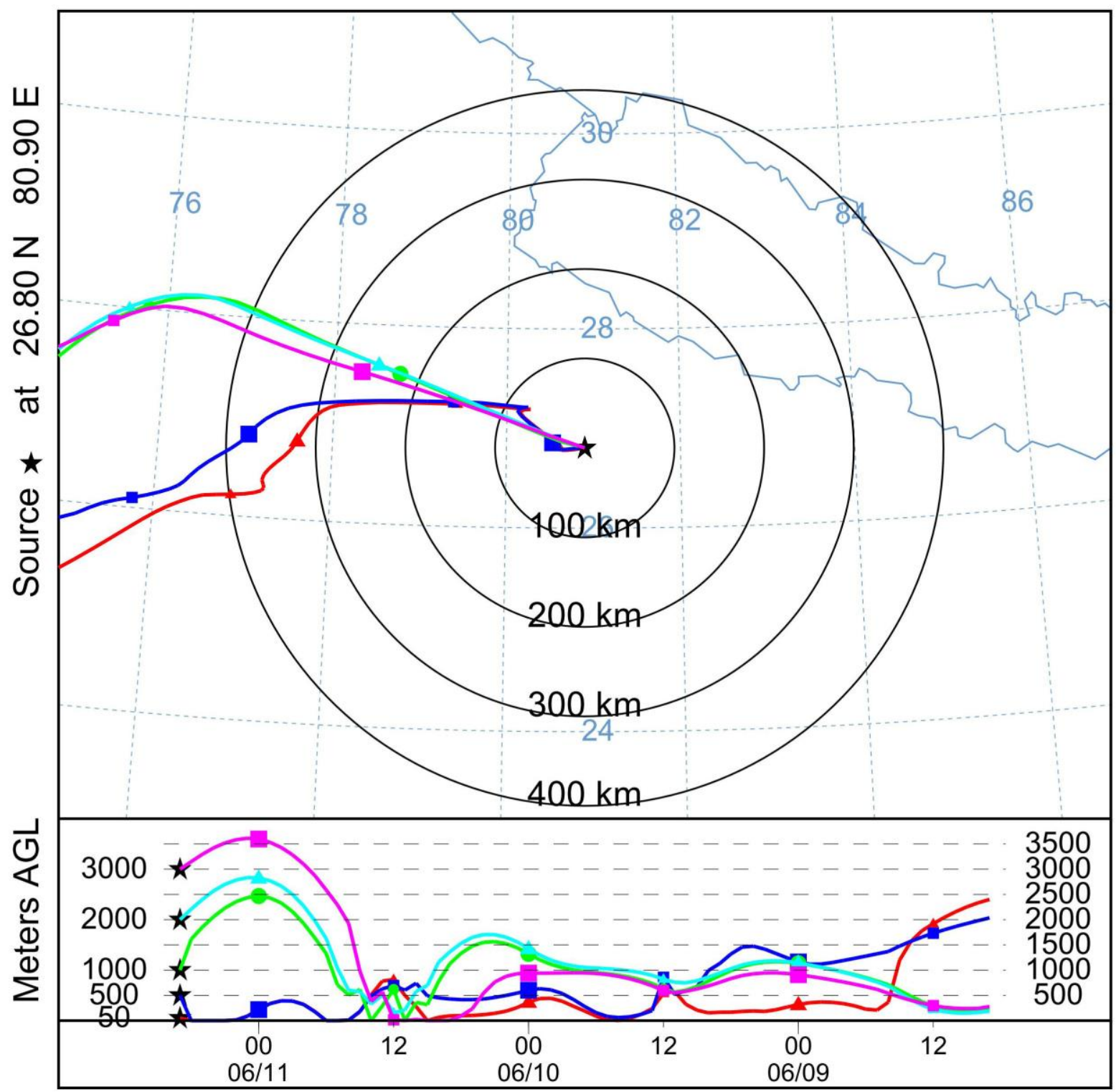

Figure S4: 72 hour back trajectory of air mass arriving at LCK on $11^{\text {th }}$ June at altitudes $50 \mathrm{~m}, 500 \mathrm{~m}, 1$ $\mathrm{km}, 2 \mathrm{~km}$ and $3 \mathrm{~km}$. 
NOAA HYSPLIT MODEL

Backward trajectories ending at 0700 UTC 12 Jun 16 CDC1 Meteorological Data

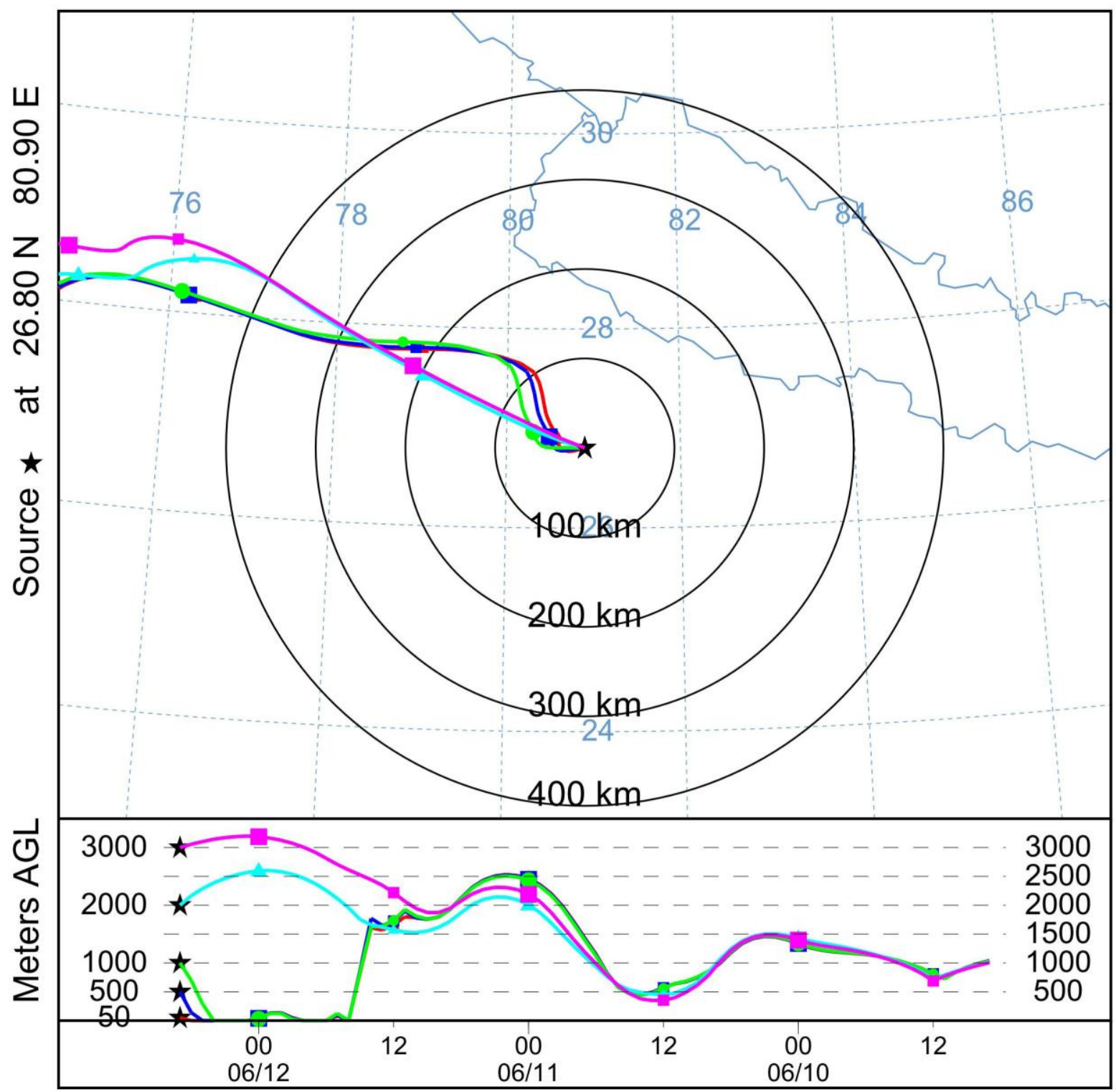

Figure S5: 72 hour back trajectory of air mass arriving at LCK on $12^{\text {th }}$ June at altitudes $50 \mathrm{~m}, 500 \mathrm{~m}, 1$ $\mathrm{km}, 2 \mathrm{~km}$ and $3 \mathrm{~km}$. 
NOAA HYSPLIT MODEL

Backward trajectories ending at 0700 UTC 13 Jun 16 CDC1 Meteorological Data

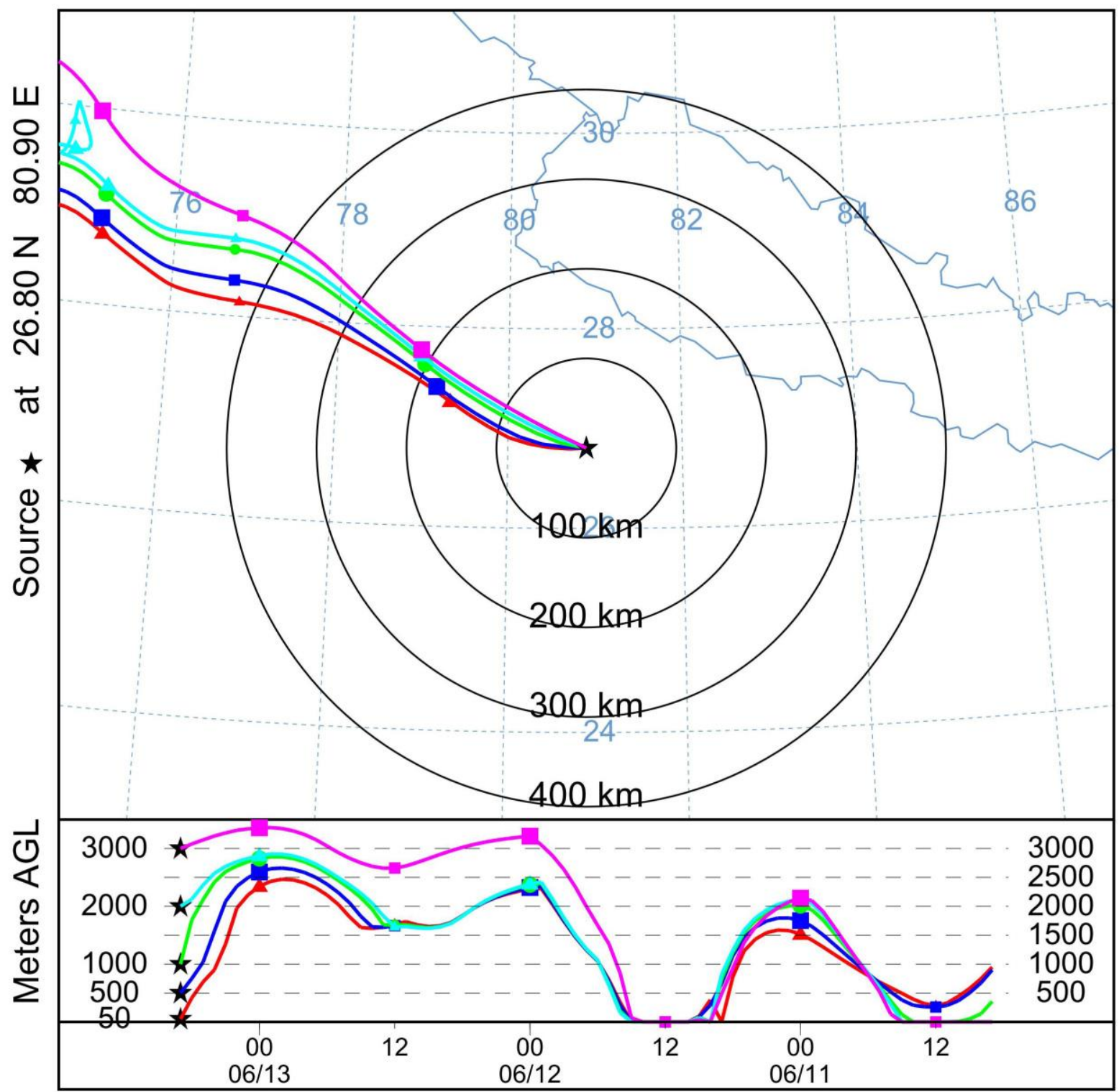

Figure S6: 72 hour back trajectory of air mass arriving at LCK on $13^{\text {th }}$ June at altitudes $50 \mathrm{~m}, 500 \mathrm{~m}, 1$ $\mathrm{km}, 2 \mathrm{~km}$ and $3 \mathrm{~km}$. 
NOAA HYSPLIT MODEL

Backward trajectories ending at 0700 UTC 07 Jul 16 CDC1 Meteorological Data

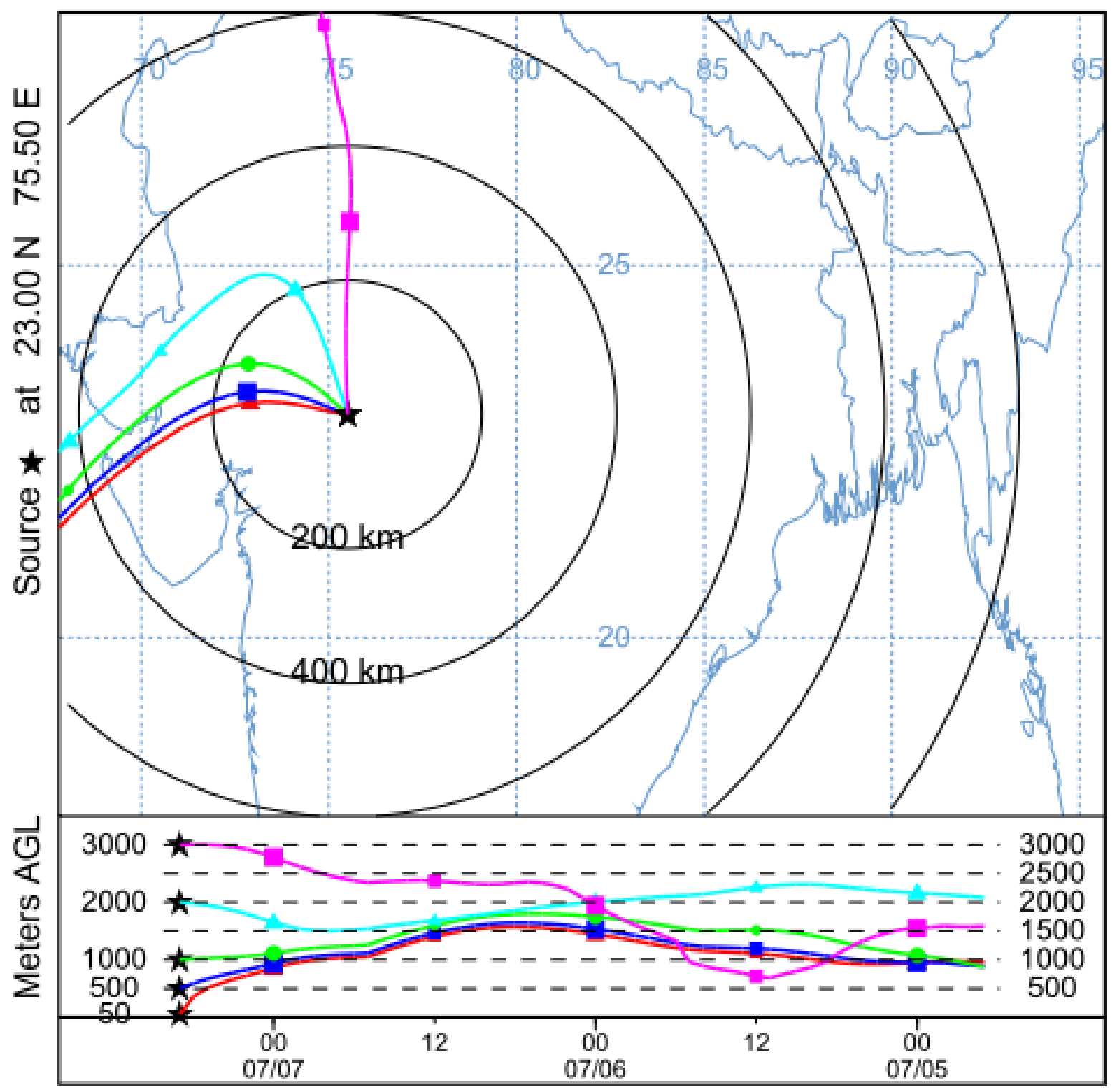

Figure S7: 72 hour back trajectory of air mass arriving at AMD on $7^{\text {th }}$ July at altitudes $50 \mathrm{~m}, 500 \mathrm{~m}, 1$ km, $2 \mathrm{~km}$ and $3 \mathrm{~km}$. 


\section{Sampling of ambient aerosols during the campaign}

The Condensation Nuclei $(\mathrm{CN})$ concentration was estimated using a modified water filled Condensation Particle Counter (CPC) TSI 3786. The modified water filled CPC which operates at a flow rate of 0.6 Litres Per Minute (LPM), is capable of detecting particles in the size range $2.5 \mathrm{~nm}$ to $>3 \mu \mathrm{m}$ and can measure concentrations up to $10^{5}$ particles $\mathrm{cm}^{-3}$. The Cloud Condensation Nuclei $(\mathrm{CCN})$ concentration was measured using a dual column Cloud Condensation Nuclei counter (CCNc; Droplet Measurement Technologies Inc. CCN-200), which is a continuousflow stream-wise thermal gradient chamber (CFSTGC) instrument. The CCN counter operated at a flow rate of 1 LPM and the flow is evenly split between the two columns. The sample to sheath flow ratio is set to 1:10 which leaves 0.05 LPM for each column for sampling. The FAAM BAe-146 has a dedicated Rosemount inlet for providing samples to the CPC and CCNc. Before reaching the instruments the sample is passed through a Nafion dryer (Permapure MD-110-12S) operated in the atmospheric vacuum set up. The drier was installed to stop relatively warm wet ambient air from condensing in the cool conditioned cabin sample lines. It was not used to force dry the sample to some set standard. The CCNc was operated behind a constant pressure inlet set to 400 $\mathrm{hPa}$. This allows a constant supersaturation to be maintained between sea level and approximately $7000 \mathrm{~m}$. All the supersaturation data and concentration data are corrected for this constant pressure using Roberts et al (2010) for the former and a simple density correction for the latter.

To gain as much information as possible from a flight, the instrument is set up to have one column scanning three different supersaturations (nominally $0.79,0.58$ and $0.38 \%$ though these will change after pressure corrections) and the other stable $(0.3 \% \mathrm{SS})$. This returns $\mathrm{CCN}$ concentrations for four different supersaturations every 15 mins and keeps one channel as a reference over the entire project. Internally a bleed air is removed from the sample line and trickled over a Rotronic HC2-IExxx Screw-in Relative Humidity (RH) and temperature sensor. This provides the sample RH and temperature measurements used here.

The mean ambient RH for the pre monsoon portion of the campaign is $49.7 \%$ this in itself is a fairly irrelevant measurement but is used to compare to the mean CCN sample line RH that is $28.7 \%$. This shows a big reduction in $\mathrm{RH}$, which is due to both the nafion and the equilibrium of the ambient air to the temperature conditions of the in-cabin sample line. The effect of this and the Nafion can be untangled to some extent by using the Magnus equation to solve RH for ambient dew point and cabin influenced sample line temperature. The data can be seen in the box plot (Figure S8) and is labelled 'theoretical' which represents the theoretical values of RH in the sample line, if the nafion is removed. The mean of this value across the three pre-monsoon SWAAMI flights is $36.1 \%$. However, a big difference can be seen in the interdecile upper range where the values are close to that of condensation, the environment the nafion dryers were used to eliminate. There are some inconsistencies in the theoretical data here (that are of little consequence) which arise from the fact that the dew point temperature from the aircraft data decomposed to $1 \mathrm{~Hz}$ is used in conjunction with the data from the Rotronic HC2-IExxx which reports every 5 seconds. The Rotronic data also has a long lag due to the small amount of bleed air used and the probe's response time. This approach falls apart for very dynamic environments or aircraft manoeuvres where there is rapid change in water vapour or temperature. However, the data are still indicative and the effect of the drying (though less pronounced can be seen) with mean values at 54.4, 73.5 and 57.6\% for sample, ambient and theoretical respectively (Figure S9). As would be expected the values are higher during the monsoon period than prior to it. 


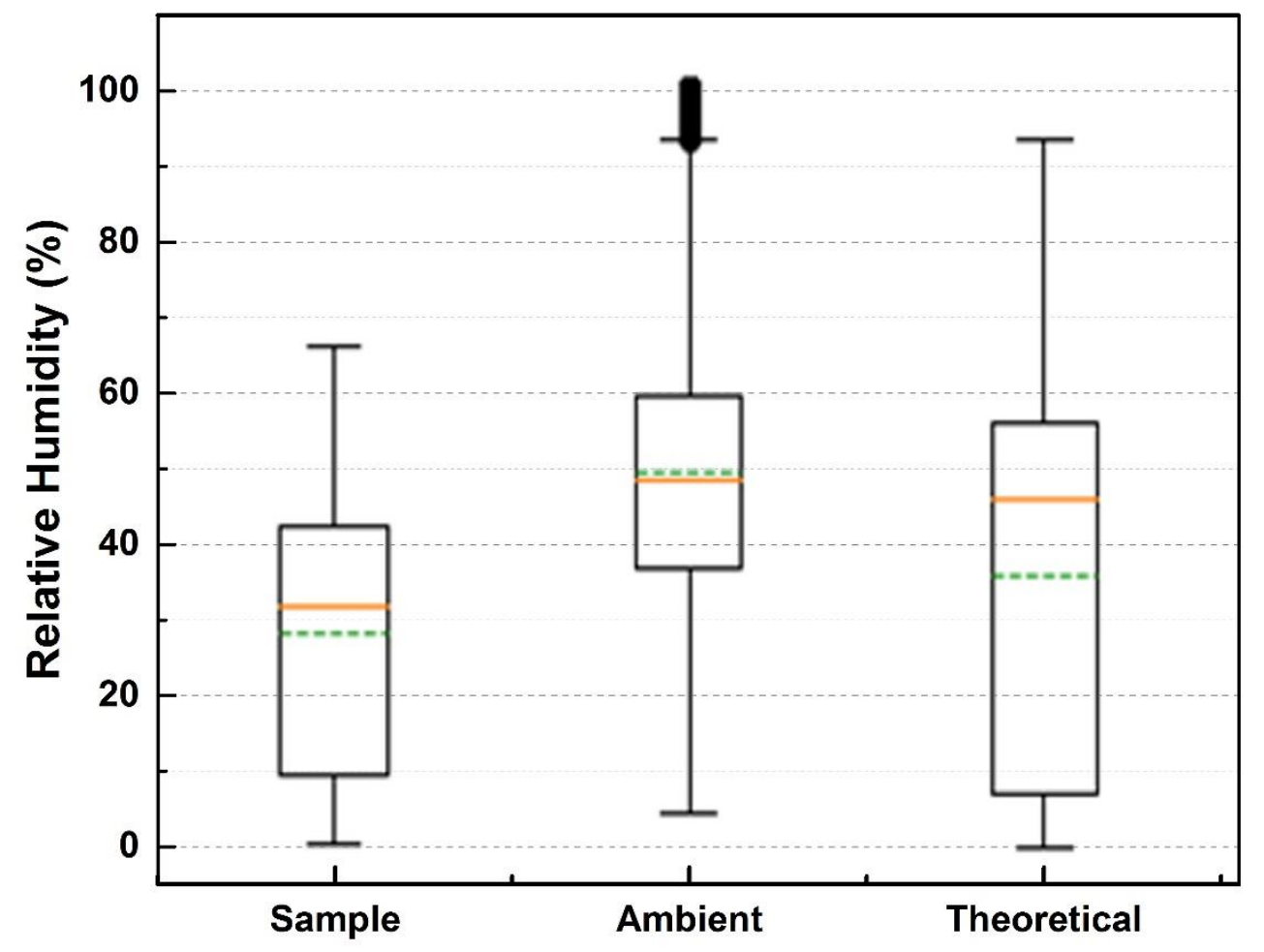

Figure S8. Boxplots showing mean (dashed green), median (solid orange), interquartile (box) and interdecile (caps) for the RH data from the three pre-onset flights (B956, B957 and B958).

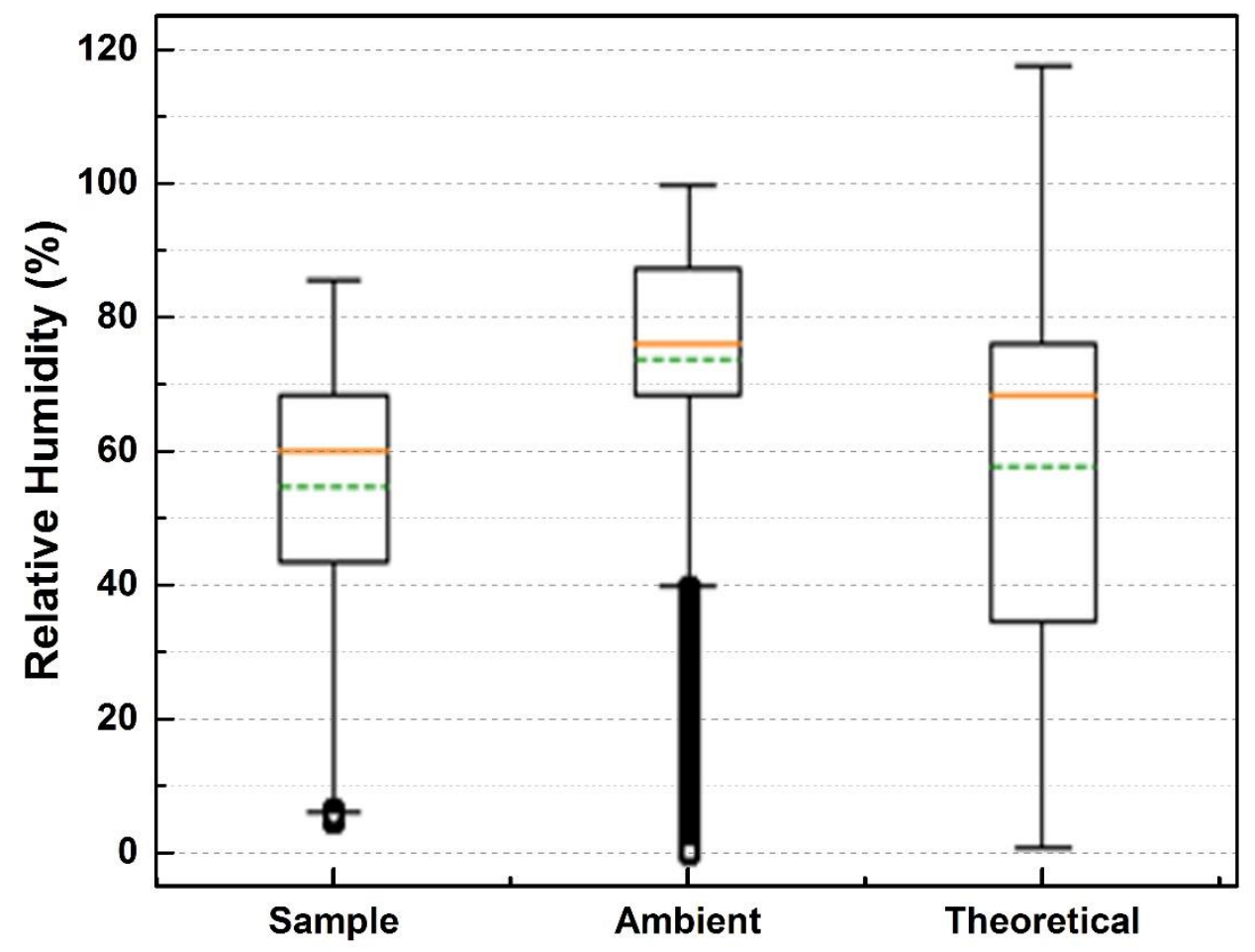

Figure S9. Boxplots showing, mean (dashed green), median (solid orange) interquartile (box) and interdecile (caps) for the RH data from the six monsoon flights (B969 to B974). 


\section{Reference}

Roberts, G. C., Day, D. A., Russell, L. M., Dunlea, E. J., Jimenez, J. L., Tomlinson, J. M., Collins, D. R., Shinozuka, Y., and Clarke, A. D.: Characterization of particle cloud droplet activity and composition in the free troposphere and the boundary layer during INTEX-B, Atmospheric Chemistry and Physics, 10, 6627-6644, 2010. 